\title{
ON A NONLINEAR VOLTERRA INTEGRODIFFERENTIAL EQUATION IN BANACH SPACES
}

\author{
M. B. DHAKNE AND S. D. KENDRE
}

\begin{abstract}
The objective of the present paper is to study the local existence, global existence, uniqueness, continuous dependence, asymptotic stability and other properties of solutions of a nonlinear Volterra integrodifferential equation in Banach spaces of more general type. The technique employed in our analysis is based on treating the equation in the domain of the infinitesimal generator of semigroups of linear operators in a Banach space with graph norm and using results from linear semigroup theory.
\end{abstract}

Mathematics subject classification (2000): 45N05, 45J05. norm.

Key words and phrases: Volterra integrodifferential equation, semigroup, infinitesimal generator, graph

\section{REFERENCES}

[1] A. Belleni MoRANTE, An integrodifferential equation arising from the theory of heat conduction in rigid material with memory, Boll. Un. Mat. Ital., 15, (1978), 470-482.

[2] A. Belleni Morante, G. F. Roach, A mathematical model for Gamma ray transport in the cardiac region, J. Math. Anal. Appl., 244, (2000), 498-514.

[3] M. B. DHAKNE, B. G. PACHPATTE, On perturbed abstract functional integrodifferential equation, Acta Mathematical Scienta., 8, (1988), 263-282.

[4] M. B. DHAKNE, B. G. PACHPATTE, On some abstract functional integrodifferential equations, Indian J. Pure and Appl. Math., 22, (1991), 109-134.

[5] M. L. HEARD, An abstract parabolic Volterra integrodifferential equation, SIAM J. Maths. Anal., 13, (1982), 81-105.

[6] T. KaTO, Perturbation theory for linear operators, 2nd ed. Grundlehrender, Math. Wissenschaften Band 132 Springer Verlag, New York, 1980.

[7] G. E. LADAS, V. LAKSHMIKANTHAM, Differential equations in abstract space, Academic press, 1972.

[8] M. HieBER, J. Pruss, Heat kernels and maximal Lp-Lq estimates for parabolic evolution equations, Commun. In Partial Differential Equations., 22, (9 and 10)(1997), 1647-1669.

[9] R. K. MiLLER, Volterra integral equations in a Banach Spaces, Funkcial Ekvac., 18, (1975), 163-194.

[10] J. A. NoHEL, Nonlinear Volterra equations for heat flow in materials with memory, in "Integral and functional differential equations" ed. T. Herdman et al, Lecture Notes in Pure And Appl. Math. 67, Dekker, New York, (1981), 3-82.

[11] A. PAZY, Semigroup of linear operators and applications to partial differential equations, Springer Verlag, New York, (1983).

[12] G. F. WeBB, An abstract semilinear Volterra integrodifferential equation, Proc. Amer. Math. Soc., 69, (1978), 255-260. 